\title{
Effects of Residual Hearing on the Auditory Steady State Response for Cochlear Implantation in Children
}

\author{
Young Seok Kim ${ }^{1}$, Sun A Han ${ }^{1}$, Hyunjun Woo ${ }^{1}$, Myung-Whan Suh ${ }^{1}$, \\ Jun Ho Lee ${ }^{1,2}$, Seung Ha Oh ${ }^{1,2}$, and Moo Kyun Park ${ }^{1,2}$ \\ ${ }^{1}$ Department of Otorhinolaryngology-Head and Neck Surgery, Seoul National University College of Medicine, Seoul, Korea \\ ${ }^{2}$ Sensory Organ Research Institute, Seoul National University Medical Research Center, Seoul, Korea
}

Received March 1, 2019

Revised March 26, 2019

Accepted April 19, 2019

Address for correspondence

Moo Kyun Park, MD, PhD

Department of Otorhinolaryngology-

Head and Neck Surgery,

Seoul National University

College of Medicine,

101 Daehak-ro Jongno-gu,

Seoul 03080, Korea

Tel +82-2-2072-2446

Fax +82-2-745-2387

E-mail aseptic@snu.ac.kr
Background and Objectives: We aim to explore the effects of residual auditory steady state response (ASSR) on cochlear implantation (Cl) outcomes in children lacking auditory brainstem responses (ABRs). Subjects and Methods: We retrospectively reviewed the data of child $\mathrm{Cl}$ recipients lacking ABRs. All ears were divided into two groups: with residual ASSR and without ASSR. For each frequency, the T- and C-levels and the electrical dynamic ranges of postoperative 3-month and 1-year mappings were compared between the groups. To evaluate speech perception, patients who received simultaneous bilateral Cls were divided into two groups: group 1 exhibited responses at all frequencies in both ears; in group 2, at least one ear evidenced no response. The Categories of Auditory Perception (CAP) and Infant-Toddler Meaningful Auditory Integration Scale (IT-MAIS) scores were compared between the groups. Results: We enrolled 16 patients. At $2 \mathrm{kHz}$, the postoperative 3-month and 1-year T-levels of patients with residual hearing were lower than those of hearing loss group ( $p=0.001, p=0.035$ ). In residual hearing group, the ASSR threshold correlated positively with the postoperative 1-year T-level $\left(p=0.012, R^{2}=0.276\right)$ and $C$-level $(p=0.002$, $\left.\mathrm{R}^{2}=0.374\right)$. Of 10 simultaneous bilateral $\mathrm{Cl}$ recipients, 5 exhibited ASSRs at all frequencies and the other 5 showed no response at $\geq 1$ frequency. The latter had higher CAP scores at the postoperative 1-year $(p=0.018)$. Conclusions: In children exhibiting hearing loss in ABR testing, residual hearing at $2 \mathrm{kHz}$ ASSR correlated positively with the post-Cl T-level. Those with ASSRs at all frequencies had significantly lower CAP scores at the postoperative 1year. $\mathrm{Cl}$ should not be delayed when marginal residual hearing is evident in ASSR.

J Audiol Otol 2019;23(3):153-159

KEY WORDS: Cochlear implantation - Auditory brainstem evoked response . Auditory evoked response $\cdot$ Sensorineural hearing loss $\cdot$ Speech perception.

\section{Introduction}

Cochlear implantation (CI) effectively restores hearing, facilitates language development and improves the quality of life [1]. Accumulating evidence shows that language development is optimal when CI is performed early [2]. Preoperative residual hearing in prelingually deaf children enhances speech perception after CI [3]. Although the identification

This is an Open Access article distributed under the terms of the Creative Commons Attribution Non-Commercial License (https://creativecommons.org/licenses/by-nc/4.0/) which permits unrestricted non-commercial use, distribution, and reproduction in any medium, provided the original work is properly cited. and preservation of residual hearing are important, behavioral audiometry is not appropriate for some CI candidate children $[2,4]$. For children who cannot undergo such audiometry, the click or tone burst auditory brainstem response (ABR) is widely used as an objective hearing measurement method. ABR stimuli are transient, not frequency-specific, and its maximum output is $90 \mathrm{~dB}$ [5]. Thus, the ABR test has certain limitations when used to assess residual hearing in those who are severely to profoundly deaf [5]. The auditory steady state response (ASSR) is a scalp-recorded auditory evoked potential elicited in response to sinusoidal and/or frequency-modulated tones [6]. The ASSR test complements the limitations 
of the ABR test: stimuli are narrowly defined in terms of frequency, the maximum stimulation is $120 \mathrm{~dB}$ because the stimulus is of long duration, and the results are delivered automatically [5,7-9]. Thus, the ASSR test is useful for estimating the hearing thresholds of patients exhibiting no ABR at the maximum stimulus [10].

Patients lacking ABRs are generally considered deaf. However, some exhibit ASSRs. Residual hearing on ASSR enhances the outcomes of CI in children with inner-ear malformations [7]. To the best of our knowledge, no study has yet analyzed the effects of residual preoperative ASSR hearing on CI outcomes in children with severe to profound hearing loss; this is the topic of this study.

\section{Subjects and Methods}

We retrospectively reviewed the relationship between the preoperative ASSR and the post-CI outcomes of children lacking ABRs. The study was approved by the Institutional Review Board of Seoul National University Hospital (IRB No. 1811-102-987).

\section{Study material}

Of all patients less than 60 months old who underwent CI (Nucleus CI 422 device) at Seoul National University Hospital (Seoul, Korea) from January 2015 to July 2017, those who lacked ABRs in both ears were initially enrolled. The inclusion criteria were the availability of preoperative ASSR and post-CI mapping data at 3 months and 1 year postoperatively. The exclusion criteria were the presence of any inner-ear anomaly, any surgical complication, developmental delay, or a comorbidity that might affect post-CI outcomes. For each frequency at $0.5,1,2$, and $4 \mathrm{kHz}$, all ears were divided into two groups by reference to the preoperative ASSR data: a residual hearing group (ASSR thresholds $\leq 110 \mathrm{~dB}$ at all frequencies) and a hearing loss group (no ASSR response upto $110 \mathrm{~dB}$ stimulation). At each frequency, the perceptional threshold (Tlevel), comfort level (C-level), and electrical dynamic range (EDR) were measured 3 months and 1 year postoperatively, and compared between the two groups.

We also compared hearing and speech evaluation data. Of all patients, those who underwent simultaneous bilateral CI were divided into two groups: group 1 (all response group) contained patients who exhibited ASSR thresholds at all frequencies in both ears; group 2 (partial response group) lacked ASSR at least one frequency in any ear. The maximum ASSR stimulus was $110 \mathrm{~dB}$, and when there is no ASSR at $110 \mathrm{~dB}$, it is assumed to be $120 \mathrm{~dB}$ and the mean ASSR threshold was calculated. Categories of Auditory Perception (CAP) scores and Infant-Toddler Meaningful Auditory Integration Scale (IT-MAIS) scores in terms of speech perception were recorded preoperatively, and 3 months and 1 year postoperatively, and compared between the groups. Patients who did not undergo postoperative 3-month or 1-year hearing and speech evaluations at our center were excluded.

\section{ABR}

ABRs and ASSRs were tested using a Bio-logic MASTER II platform (Navigator Pro, Bio-Logic, San Carlos, CA, USA). All children lay on a bed in a soundproof room and were sedated with oral pocral syrup $(50 \mathrm{mg} / \mathrm{kg}$ ). Electroencephalographic activity was recorded using gold disk electrodes placed on the mastoid and high forehead or vertex. The ground was placed on the forehead. The inter-electrode impedance was $<3-5 \mathrm{k} \Omega$. Click stimuli (duration: $100 \mathrm{~ms}$ ) were presented through ER3A inset earphones (Etymotic Research Inc., Elk Grove Village, IL, USA) at a maximum of $90 \mathrm{~dB}$ HL at 11.132.1/s with alternating polarity. Thresholds were determined at $5 \mathrm{~dB}$ intervals. A response was considered absent when the $90 \mathrm{~dB}$ wave triggered no response.

\section{ASSR}

Surface recording electrodes were placed on the forehead (ground) and the mastoid (reference). A disk electrode was placed at the vertex (active). The electrode impedances were $<5 \mathrm{k} \Omega$. Air-conducted stimuli were presented to both ears via ER3A inset earphones. Four carrier frequencies were tested $(0.5,1,2$, and $4 \mathrm{kHz})$; all were $100 \%$ amplitude-modulated and $20 \%$ frequency-modulated at modulation frequencies of 82, 87, 91, and $96 \mathrm{~Hz}$ (left side) and 84, 89, 94, and $99 \mathrm{~Hz}$ (right side), at intensities $\leq 80 \mathrm{~dB}$ HL. At intensities $\geq 90 \mathrm{~dB}$ $\mathrm{HL}$, the modulation frequencies were $67 \mathrm{~Hz}$ (left side) and $69 \mathrm{~Hz}$ (right side). The maximum presentation level was 110 dB HL. During each recording, 16-32 sweeps were made in each block; data were averaged in the time domain and subjected to fast Fourier transformation. Response level significance was set to $p<0.05$ and was monitored after each sweep.

\section{Mapping}

The mapping strategy was identical for all patients (advanced combination encoder, monopolar $1+2$; pulse width $=25$, sensitivity=12). For each patient, the T-level was the lowest current level (CL) eliciting an auditory sensation. The C-level was the highest CL that was not uncomfortably loud. The EDR was the difference between the C-and T-levels [11]. The electrical channels delivered data derived at various frequencies; electrodes 20, 16, 11, and 6 yielded most data for $0.5,1,2$, and $4 \mathrm{kHz}$, respectively. A CP 920 processor or CP950 Kan- 
so processor (Cochlear Ltd., Sydney, Australia) were used.

\section{Auditory performance evaluation}

Hearing was evaluated at 3 months and 1 year postoperatively, depending on patient age. The CAP score lies on an eight-point hierarchical scale ranging from no awareness of environmental sound (category 0 ) to conversational use of the telephone with a known speaker (category 7) [12]. The IT-MAIS score was calculated based on the answers given by caregivers; the instrument includes 10 items in three domains: vocalization behavior (items $1-2$ ), alerting to sounds (items 3-6), and deriving meanings from sounds (items 710). Each item is scored from 0 to 4 : 0 , never; 1 , rarely $(25 \%)$; 2 , occasionally $(50 \%) ; 3$, frequently $(75 \%)$; and 4 , always $(100 \%)$ [13].

\section{Statistical analyses}

The independent-samples t-test was used to compare the Tand C-levels and the EDRs of the two groups at 0.5, 1, 2, and $4 \mathrm{kHz}$. The correlations between T- and C-levels, and ASSR thresholds, were analyzed via simple linear regression and calculation of Pearson correlation coefficients. The MannWhitney U-test was employed to compare the CAP and ITMAIS scores. A $p$-value $<0.05$ was considered to reflect statistical significance. All analyses were performed using SPSS software (ver. 20.0; IBM Corp., Armonk, NY, USA).

\section{Results}

\section{Post-implant mapping results}

We enrolled 16 patients (4 boys and 12 girls; 30 ears, 8 boys' and 22 girls') with a mean age of $17.0 \pm 5.7$ months. Thirteen underwent simultaneous CI, one underwent CI of both ears in 1-year interval, and two underwent right-ear CI only. At each frequency, all ears were divided into those with and without residual hearing. At all frequencies, the mean age and sex distributions of the two groups did not differ significantly (Table 1). At $2 \mathrm{kHz}$, a significant relationship was apparent between the preoperative ASSR and the post-CI outcome. At $2 \mathrm{kHz}$, the postoperative 3-month and 1-year T-levels of those with residual hearing were lower than those of patients with no hearing ( $p=0.001, p=0.035$ ) (Fig. 1). Simple linear regression showed that the ASSR threshold correlated positively (but weakly) with the postoperative 1-year T-level ( $p=0.012$, $\left.\mathrm{R}^{2}=0.276\right)$ and C-level $\left(p=0.002, \mathrm{R}^{2}=0.374\right)$; the C-level correlation was better (Fig. 2).

\section{Auditory performance}

Of the 13 patients who underwent simultaneous bilateral

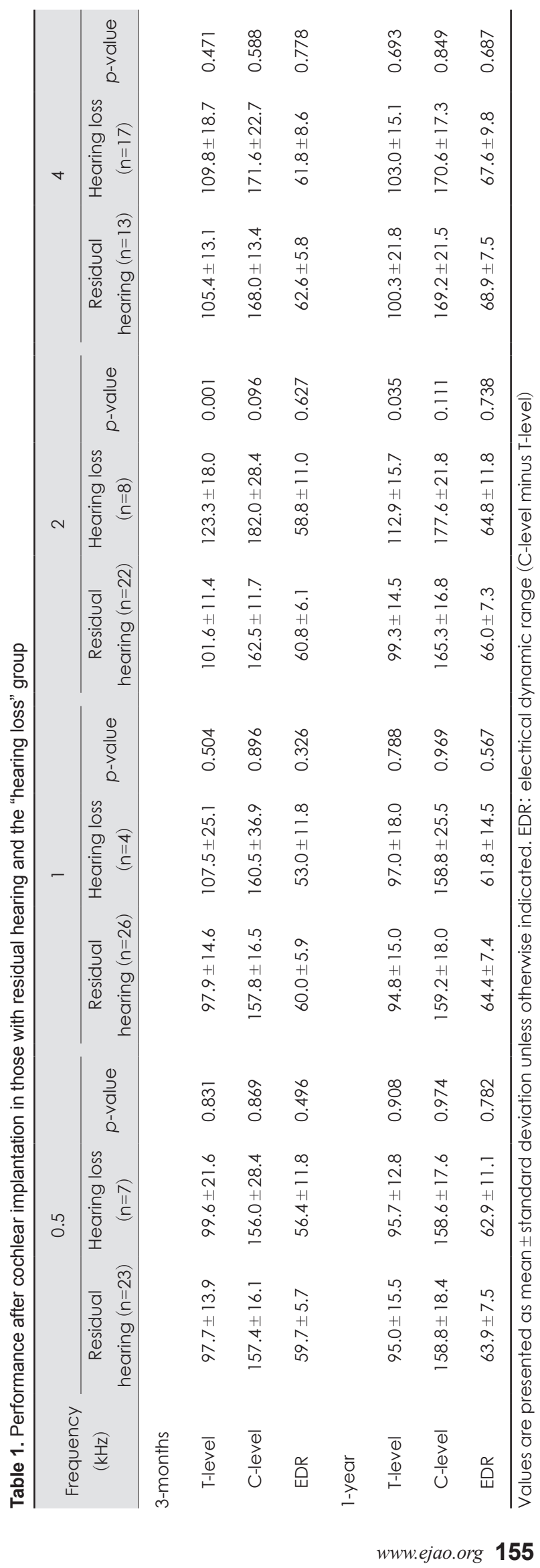




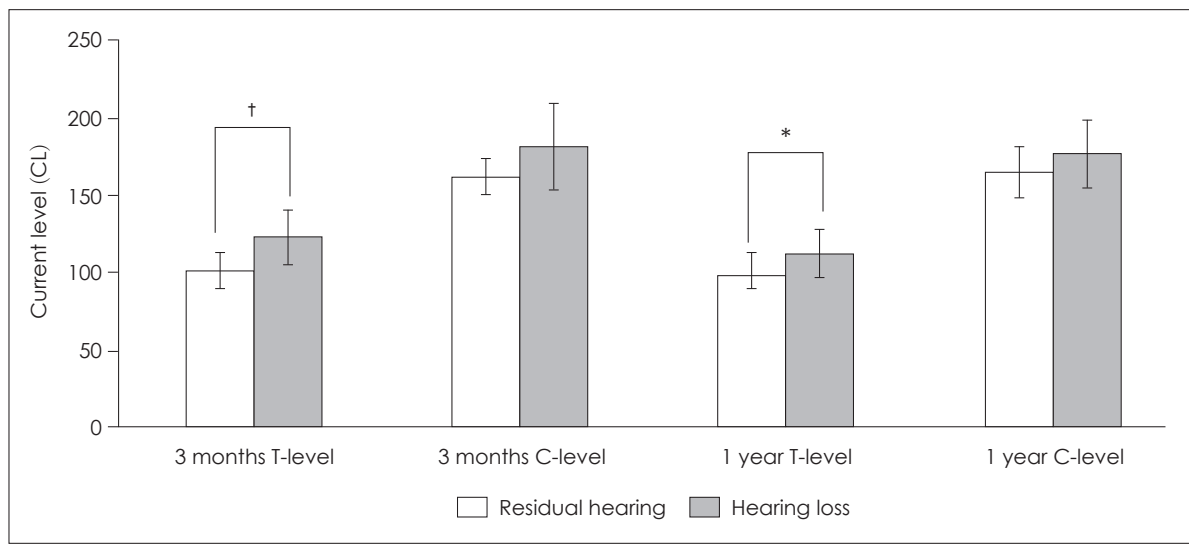

Fig. 1. Auditory performance after cochlear implantation. At $2 \mathrm{kHz}$, the T-levels 3 months and 1 year postoperatively of the residual hearing group were higher than those of the hearing loss group. ${ }^{*} p<0.05,{ }^{\dagger} p<0.01$.
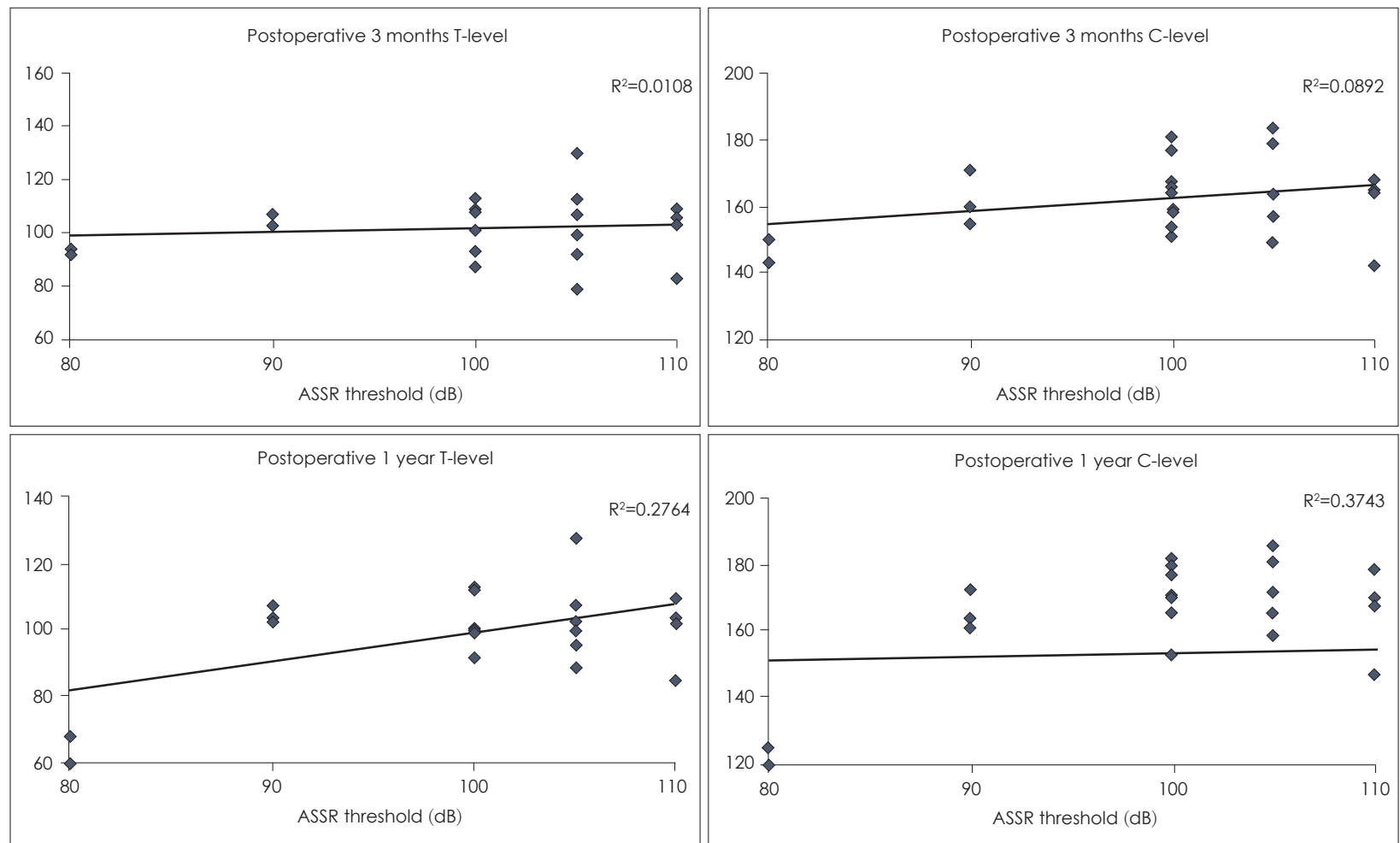

Fig. 2. Correlations between ASSR thresholds and T- and C-levels at $2 \mathrm{kHz}$. At 3 months and 1 year post-operation, the ASSR thresholds correlated weakly with the $2 \mathrm{kHz}$ T- and C-levels. ASSR: auditory steady state response.

CIs, 3 were excluded because of the absence of speech evaluation data. The remaining 10 patients were divided into group 1 (responses at all frequencies, $\mathrm{n}=5$ ) and group 2 (no response at $\geq 1$ frequency, $n=5$ ). The mean patient age at the time of CI was 14.9 months, but group 1 patients tended to undergo CI later (17.6 months vs.12.2 months, $p=0.105$ ) (Table 2). Compared to group 1, group 2 exhibited a significantly higher CAP score at the postoperative 1-year speech evaluation (2.6 vs. 5.0, $p=0.018$ ); the IT-MAIS score was also higher in group 2 , but statistical significance was not attained (26.6 vs. 40.0, $p=0.054$ ). All group 2 patients achieved CAP scores of 5 and IT-MAIS scores of 40, but patients 1, 2, 4, and 5 of group 1 did not attain such scores (Fig. 3).

\section{Discussion}

We investigated the effects of ASSR residual hearing on the CI outcomes of children lacking ABRs. When the ABRs are bilateral absent, the possibility of residual hearing is not precluded [14]. We found that ASSR residual hearing improved CI outcomes. ASSRs yield useful information on children lacking ABRs. However, the group with residual hearing on ASSR exhibited a significantly poorer CAP score 1 year postoperatively. 
First described by Galambos et al. in 1981, ASSR testing has evolved considerably and is now widely used $[15,16]$. Strong correlations are evident between behavioral audiometry and ASSR data; the differences fall as the severity of hear-

Table 2. Auditory performance of subgroups according to ASSR response

\begin{tabular}{|c|c|c|c|}
\hline & Group 1 & Group 2 & \multirow{2}{*}{$\begin{array}{c}\mathrm{p}- \\
\text { value }\end{array}$} \\
\hline & $\begin{array}{c}\text { (all response) } \\
(n=5)\end{array}$ & $\begin{array}{l}\text { artial response }) \\
\qquad(\mathrm{n}=5)\end{array}$ & \\
\hline Age (months) & $17.6 \pm 5.1$ & $12.2 \pm 1.3$ & 0.105 \\
\hline $\begin{array}{l}\text { Mean ASSR } \\
\text { threshold (dB) }\end{array}$ & $97.8 \pm 7.1$ & $110.3 \pm 6.0$ & 0.016 \\
\hline \multicolumn{4}{|l|}{ CAP score } \\
\hline Preop. CAP & $0.2 \pm 0.4$ & $0.2 \pm 0.4$ & 1.000 \\
\hline Postop. 3 months CAP & $1.4 \pm 0.9$ & $3.2 \pm 1.5$ & 0.055 \\
\hline Postop. 1 year CAP & $2.6 \pm 1.5$ & $5.0 \pm 0.0$ & 0.018 \\
\hline \multicolumn{4}{|l|}{ IT-MAIS } \\
\hline Preop. IT-MAIS & $4.6 \pm 3.4$ & $1.0 \pm 1.0$ & 0.108 \\
\hline $\begin{array}{l}\text { Postop. } 3 \text { months } \\
\text { IT-MAIS }\end{array}$ & $15.0 \pm 11.0$ & $21.4 \pm 8.4$ & 0.248 \\
\hline Postop. 1 year IT-MAIS & $26.6 \pm 13.1$ & $40.0 \pm 0.0$ & 0.054 \\
\hline
\end{tabular}

Values are presented as mean \pm standard deviation unless otherwise indicated. ASSR: auditory steady state response, CAP: Categories of Auditory Perception, IT-MAIS, Infant-Toddler Meaningful Auditory Integration Scale, Preop.: preoperative, Postop.: postoperative ing loss increases [17-23]. The mean differences between the ASSR and behavioral thresholds are $0-17 \mathrm{~dB}$ for adults with normal hearing and 5-13 $\mathrm{dB}$ for those with mild to severe sensorineural hearing loss (SNHL) [15]. Rance and Briggs [22] reported significant positive correlations $(r=0.81-0.93)$ between ASSR and behavioral hearing thresholds at 250$4,000 \mathrm{~Hz}$ in 184 infants with moderate to profound SNHL. Han, et al. [23] also reported strong correlations $(r=0.91-0.93)$ between these two measurements in 40 young children (aged 6 months to 5 years) with SNHL. Beck, et al. [21] reported that, among pediatric CI candidates, the mean difference between the ASSR and behavioral thresholds was 0.09-8.94 $\mathrm{dB}$, and an absent ASSR was a strong predictor of profound hearing loss as evidenced by the behavioral threshold (specificity $>90 \%$ ).

Preoperative residual hearing evident in behavioral audiometry improves speech perception and language development after CI in prelingually deaf children [3]. Several studies have explored the effects of residual preoperative hearing on the outcomes of electrophysiolocal procedures and CI. Kileny, et al. [24] found that the preoperative, electrical, promontory stimulation threshold predicted post-CI speech and sound recognition in 10 patients. Jeon, et al. [25] reported that patients with auditory neuropathy spectrum disorder who exhibited electrically evoked auditory brainstem responses (EABRs) per-

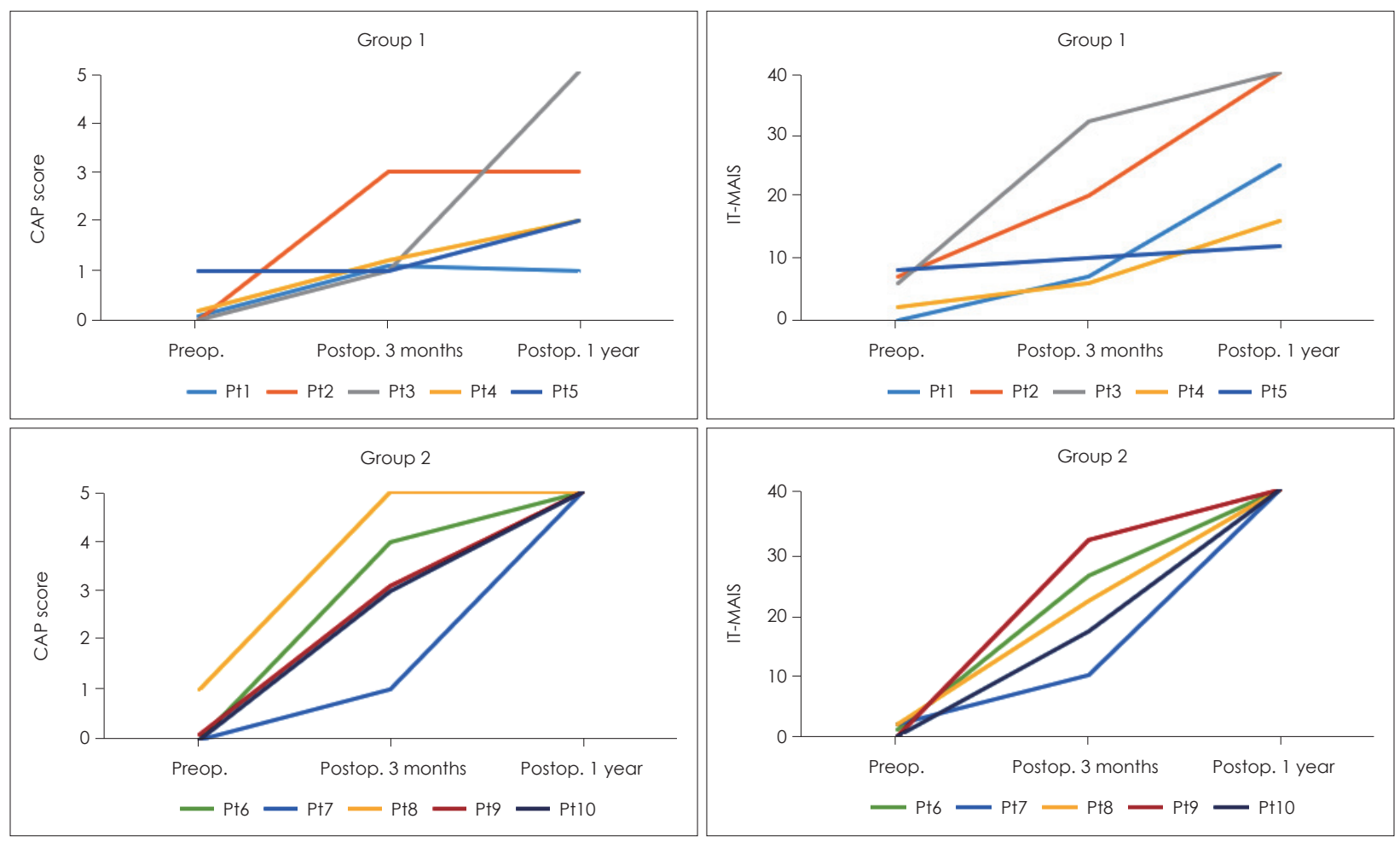

Fig. 3. Changes in CAP and IT-MAIS scores after cochlear implantation. Group 1 (evidencing responses at all frequencies) had poorer CAP and IT-MAIS scores than group 2 (lacking a response at $\geq 1$ frequency) after 1 year. CAP: Categories of Auditory Perception, ITMAIS: Infant-Toddler Meaningful Auditory Integration Scale, Pt1-10: patients 1-10, Preop.: preoperative, Postop.: postoperative. 
formed better after CI (in terms of the CAP score) than those lacking EABRs. Kuo and Gibson [26] reported that CI recipients aged 10-15 years old found it more difficult than younger children to learn speech perception and production. However, in such patients, residual hearing at $2-4 \mathrm{kHz}$ prior to CI correlated positively with more rapid improvement [26]. Cowan, et al. [27] reviewed 117 children who had undergone $\mathrm{CI}$ and found that those with better preoperative residual hearing scored significantly higher on open-set word and sentence perception tests when using the implant alone. Qiao, et al. [7] studied 72 children with inner-ear malformations who received multichannel CIs. At low, moderate, and high frequencies $(0.5,1-2$, and $4 \mathrm{kHz}$, respectively), the behavioral T-levels 1 year after implantation were significantly lower in those with residual hearing compared to those with hearing loss $(p<0.01)$ [7]. They found that the preoperative ASSR thresholds significantly correlated with the postoperative EABR thresholds $(p<0.01, \mathrm{r}=0.48-0.88)$.

The $2 \mathrm{kHz}$ T-level after CI differed significantly between those with and without residual hearing. We also found weak associations between the ASSR threshold and the postoperative 1-year T- and C-levels. At other frequencies, we found no such relationship. One possible explanation is that the 2 $\mathrm{kHz}$ ASSR test measures residual hearing more accurately than ASSR tests at other frequencies. Although ASSR and behavioral audiometry data are well-correlated, the ASSR test may underestimate residual hearing to greater extent than behavioral tests [28]. Compared to behavioral audiometry, the ASSR at $2 \mathrm{kHz}$ was associated with higher positive and negative predictive values than at other frequencies [18]. In CI candidates aged 6-72 months old, the $2 \mathrm{kHz}$ ASSR test exhibited a higher sensitivity and specificity and a lower mean difference than did visual reinforcement audiometry [21]. However, artifact-like responses to high-intensity ASSR tests, particularly at 0.5 and $1 \mathrm{kHz}$, may introduce errors [10,29]. In addition, the hearing loss group may have included patients with hearing thresholds $>110 \mathrm{~dB}$. To avoid cochlear damage, we set the maximum stimulus to $110 \mathrm{~dB}$ [21]. Neither the T- nor Clevel stabilizes for several months after $\mathrm{CI}$; children require more time than adults [30]. The C-level reflects a loud but comfortable level. The T-level reportedly stabilizes earlier and is more reliable than the C-level [30].

We found that residual hearing on ASSR was significantly (negatively) related to the 1-year postoperative outcome. In addition, the CAP and IT-MAIS scores tended to be higher in patients who lacked an ASSR at $\geq 1$ frequency, although statistical significance was not attained (this was the opposite of what we expected). However, as shown in Fig. 3, patients 4 and 5 (who underwent CI 21 and 24 months old respectively, older than other patients) greatly affected the results. It is well known that early implantation to stimulate the hearing pathway during sensitive period for language acquisition gives deaf children the best chance to close the language gap to their peers [2]. Speech perception and language development after $\mathrm{CI}$ are also affected by multiple factors including the educational environment and the extent of family engagement in therapy [3]. Thus, we believe that age at implantation, consistency of CI usage, and efficacy of post-CI therapy all markedly affect speech perception. CI should not be delayed even though marginal residual hearing is evident in the ASSR test.

Our study had certain limitations. Our sample size was small. Because our patients were young at the time of CI, most could not undergo behavioral audiometry or speech evaluation using the Phonetically Balanced Word List, vowel or consonant tests, or a sentence test.

In conclusion, for child patients who exhibited hearing loss in preoperative ABR evaluations, residual hearing on ASSR at $2 \mathrm{kHz}$ improved the post-CI T-level. Weak associations were apparent between the ASSR threshold and the postoperative 1 year T- and C-levels. Of patients who underwent simultaneous bilateral CIs, those exhibiting better ASSRs at all frequencies exhibited lower CAP scores at the postoperative 1-year speech evaluation, possibly because they were older at the time of operation. Thus, we strongly recommend CI even though there is marginal residual hearing from ASSR test in child patients.

\section{Conflicts of interest}

The authors have no financial conflicts of interest.

\section{Author Contributions}

Conceptualization: Young Seok Kim and Moo Kyun Park. Data curation: Young Seok Kim, Sun A Han, and Hyunjun Woo. Formal analysis: Young Seok Kim. Funding acquisition: Moo Kyun Park. Investigation: Young Seok Kim. Methodology: Young Seok Kim, Myung-Whan Suh, Jun Ho Lee, Seung Ha Oh, and Moo Kyun Park. Project administration: Moo Kyun Park. Resources: Young Seok Kim, Sun A Han, and Hyunjun Woo. Software: Young Seok Kim, Sun A Han, and Hyunjun Woo. Supervision: Moo Kyun Park. Validation: Myung-Whan Suh, Jun Ho Lee, Seung Ha Oh, and Moo Kyun Park. Visualization: Young Seok Kim, Sun A Han, and Hyunjun Woo. Writing — original draft: Young Seok Kim. Writing — review \& editing: Young Seok Kim and Moo Kyun Park.

\section{ORCID iDs}

Young Seok Kim

Sun A Han

Hyunjun Woo

Myung-Whan Suh

Jun Ho Lee

Seung $\mathrm{Ha} \mathrm{Oh}$

Moo Kyun Park https://orcid.org/0000-0002-5042-6048 https://orcid.org/0000-0001-7646-8038 https://orcid.org/0000-0002-7822-2151 https://orcid.org/0000-0003-1301-2249 https://orcid.org/0000-0003-1284-5070 https://orcid.org/0000-0002-8635-797X https://orcid.org/0000-0002-5519-3263 


\section{REFERENCES}

1) Martini A, Bovo R, Trevisi P, Forli F, Berrettini S. Cochlear implant in children: rational, indications and cost/efficacy. Minerva Pediatr 2013;65:325-39.

2) Holt RF, Svirsky MA. An exploratory look at pediatric cochlear implantation: is earliest always best? Ear Hear 2008;29:492-511.

3) Chiossi JSC, Hyppolito MA. Effects of residual hearing on cochlear implant outcomes in children: a systematic-review. Int J Pediatr Otorhinolaryngol 2017;100:119-27.

4) Cullen RD, Higgins C, Buss E, Clark M, Pillsbury HC 3rd, Buchman CA. Cochlear implantation in patients with substantial residual hearing. Laryngoscope 2004;114:2218-23.

5) Rance G, Dowell RC, Rickards FW, Beer DE, Clark GM. Steadystate evoked potential and behavioral hearing thresholds in a group of children with absent click-evoked auditory brain stem response. Ear Hear 1998;19:48-61.

6) Picton TW, Skinner CR, Champagne SC, Kellett AJ, Maiste AC. Potentials evoked by the sinusoidal modulation of the amplitude or frequency of a tone. J Acoust Soc Am 1987;82:165-78.

7) Qiao XF, Li X, Wang D, Li TL. Correlation between preoperative auditory steady-state response and postoperative electrically evoked auditory brainstem response and $\mathrm{T}$ level in cochlear implantation for child patients with inner-ear malformations. ORL J Otorhinolaryngol Relat Spec 2018;80:51-7.

8) Kandogan T, Dalgic A. Reliability of Auditory Steady-State Response (ASSR): comparing thresholds of Auditory Steady-State Response (ASSR) with Auditory Brainstem Response (ABR) in children with severe hearing loss. Indian J Otolaryngol Head Neck Surg 2013;65 (Suppl 3):604-7.

9) Gorga MP, Neely ST, Hoover BM, Dierking DM, Beauchaine KL, Manning C. Determining the upper limits of stimulation for auditory steady-state response measurements. Ear Hear 2004;25:302-7.

10) Swanepoel D, Hugo R. Estimations of auditory sensitivity for young cochlear implant candidates using the ASSR: preliminary results. Int J Audiol 2004;43:377-82.

11) Shapiro WH, Bradham TS. Cochlear implant programming. Otolaryngol Clin North Am 2012;45:111-27.

12) Archbold S, Lutman ME, Marshall DH. Categories of auditory performance. Ann Otol Rhinol Laryngol Suppl 1995;166:312-4.

13) Zhong Y, Xu T, Dong R, Lyu J, Liu B, Chen X. The analysis of reliability and validity of the IT-MAIS, MAIS and MUSS. Int J Pediatr Otorhinolaryngol 2017;96:106-10.

14) Rance G, Rickards F. Prediction of hearing threshold in infants using auditory steady-state evoked potentials. J Am Acad Audiol 2002;13: 236-45.

15) Korczak P, Smart J, Delgado R, Strobel TM, Bradford C. Auditory steady-state responses. J Am Acad Audiol 2012;23:146-70.

16) Galambos R, Makeig S, Talmachoff PJ. A 40-Hz auditory potential recorded from the human scalp. Proc Natl Acad Sci U S A 1981;78: 2643-7.
17) Attias J, Buller N, Rubel Y, Raveh E. Multiple auditory steady-state responses in children and adults with normal hearing, sensorineural hearing loss, or auditory neuropathy. Ann Otol Rhinol Laryngol 2006; 115:268-76.

18) Ramos HF, Grasel SS, Beck RM, Takahashi-Ramos MT, Ramos $\mathrm{BF}$, de Almeida ER, et al. Evaluation of residual hearing in cochlear implants candidates using auditory steady-state response. Acta Otolaryngol 2015;135:246-53.

19) Rance G, Rickards FW, Cohen LT, De Vidi S, Clark GM. The automated prediction of hearing thresholds in sleeping subjects using auditory steady-state evoked potentials. Ear Hear 1995;16:499-507.

20) Yang $\mathrm{CH}$, Chen HC, Hwang CF. The prediction of hearing thresholds with auditory steady-state responses for cochlear implanted children. Int J Pediatr Otorhinolaryngol 2008;72:609-17.

21) Beck RM, Grasel SS, Ramos HF, Almeida ER, Tsuji RK, Bento RF, et al. Are auditory steady-state responses a good tool prior to pediatric cochlear implantation? Int J Pediatr Otorhinolaryngol 2015;79: 1257-62.

22) Rance G, Briggs RJ. Assessment of hearing in infants with moderate to profound impairment: the Melbourne experience with auditory steady-state evoked potential testing. Ann Otol Rhinol Laryngol Suppl 2002;189:22-8.

23) Han D, Mo L, Liu H, Chen J, Huang L. Threshold estimation in children using auditory steady-state responses to multiple simultaneous stimuli. ORL J Otorhinolaryngol Relat Spec 2006;68:64-8.

24) Kileny PR, Zimmerman-Phillips S, Kemink JL, Schmaltz SP. Effects of preoperative electrical stimulability and historical factors on performance with multichannel cochlear implant. Ann Otol Rhinol Laryngol 1991;100:563-8.

25) Jeon JH, Bae MR, Song MH, Noh SH, Choi KH, Choi JY. Relationship between electrically evoked auditory brainstem response and auditory performance after cochlear implant in patients with auditory neuropathy spectrum disorder. Otol Neurotol 2013;34:1261-6.

26) Kuo SC, Gibson WP. The influence of residual high-frequency hearing on the outcome in congenitally deaf cochlear implant recipients. Am J Otol 2000;21:657-62.

27) Cowan RS, DelDot J, Barker EJ, Sarant JZ, Pegg P, Dettman S, et al. Speech perception results for children with implants with different levels of preoperative residual hearing. Am J Otol 1997;18(6 Suppl): S125-6.

28) Grasel SS, de Almeida ER, Beck RM, Goffi-Gomez MV, Ramos HF, Rossi AC, et al. Are auditory steady-state responses useful to evaluate severe-to-profound hearing loss in children? Biomed Res Int 2015;2015:579206.

29) Small SA, Stapells DR. Artifactual responses when recording auditory steady-state responses. Ear Hear 2004;25:611-23.

30) Gajadeera EA, Galvin KL, Dowell RC, Busby PA. The change in electrical stimulation levels during 24 months postimplantation for a large cohort of adults using the nucleus(R) cochlear implant. Ear Hear 2017;38:357-67. 